\title{
Prevalence and patterns of hearing impairment in Egypt: a national household survey
}

O. Abdel-Hamid, ${ }^{1}$ O.M.N. Khatib, ${ }^{2}$ A. Aly, ${ }^{3}$ M. Morad ${ }^{4}$ and S. Kamel ${ }^{1}$

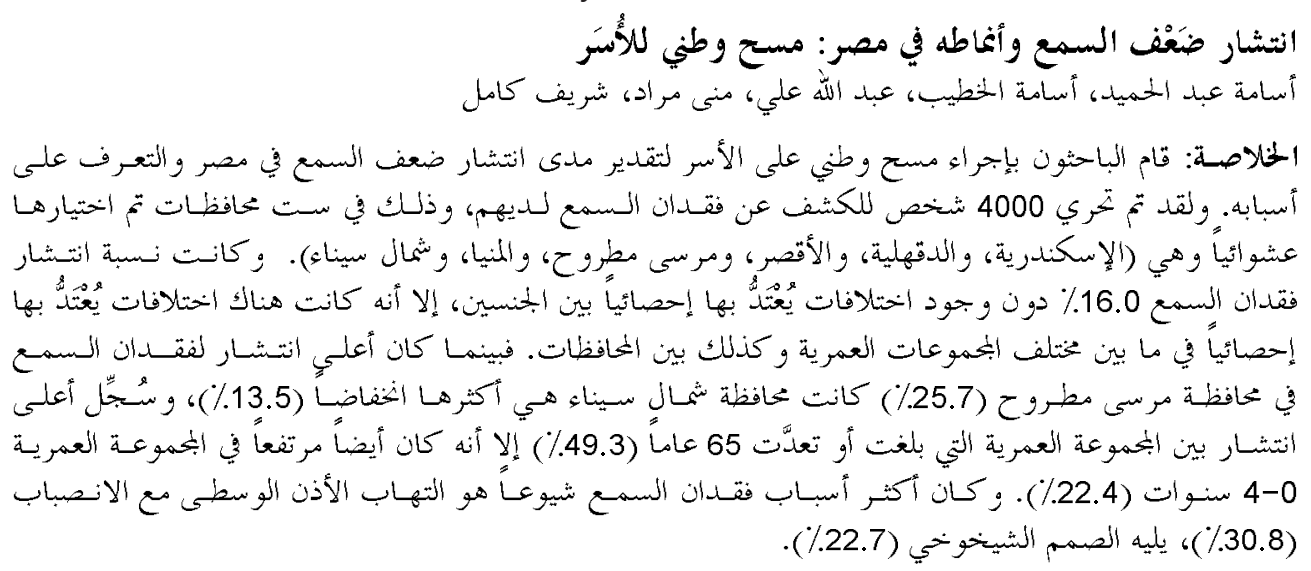

ABSTRACT We conducted a national household survey to estimate the prevalence and causes of hearing impairment in Egypt. From 6 randomly selected governorates (Alexandria, Dakahlia, Luxor, Marsa Matrouh, Minia and North Sinai), 4000 individuals were screened for hearing loss. The prevalence of hearing loss was $16.0 \%$ with no significant sex differences. There were significant differences between the age groups and governorates: Marsa Matrouh had the highest prevalence of hearing loss $(25.7 \%)$ and North Sinai the lowest $(13.5 \%)$; those $\geq 65$ years had the highest prevalence $(49.3 \%)$, but it was also high in those aged $0-4$ years $(22.4 \%)$. Otitis media with effusion $(30.8 \%)$ was the commonest cause of hearing loss, followed by presbycusis $(22.7 \%)$.

Prévalence et formes de la déficience auditive en Égypte : enquête nationale auprès des ménages

RÉSUMÉ Une enquête nationale a été menée auprès des ménages égyptiens afin d'évaluer la prévalence et les causes de la déficience auditive dans ce pays. Il a été procédé à un dépistage de la surdité chez 4000 habitants de 6 gouvernorats (Alexandrie, Dakahlia, Louxor, Marsa Matrouh, Minia et NordSinaï) sélectionnés au hasard. L'enquête fait apparaître une prévalence de la perte auditive de 16,0 \%, sans influence significative du sexe. Des différences significatives s'observent entre les tranches d'âge et d'un gouvernorat à l'autre : c'est dans le gouvernorat de Marsa Matrouh que l'on constate la plus forte prévalence de la surdité $(25,7 \%)$ et dans le Nord-Sinaï que l'on enregistre la plus faible $(13,5 \%)$. Quant aux tranches d'âge, la plus forte prévalence touche celle des 65 ans et plus $(49,3 \%)$, mais elle s'avère également élevée chez les $0-4$ ans $(22,4 \%)$. L'otite moyenne sécrétoire $(30,8 \%)$ apparaît comme la cause la plus fréquente de perte auditive, suivie de la presbyacousie $(22,7 \%)$.

${ }^{1}$ Department of Otolaryngology, Ain Shams University, Cairo, Egypt.

${ }^{2}$ Noncommunciable Diseases Unit, Division of Health Promotion and Protection, World Health Organization Regional Office for the Eastern Mediterranean, Cairo, Egypt (Correspondence to O.M.N. Khatib: Khatibo@ emro.who.int).

${ }^{3}$ Department of Otolaryngology, Hearing and Speech Institute, Cairo, Egypt.

${ }^{4}$ Department of Audiology, University of Alexandria, Alexandria, Egypt.

Received: 26/12/05; accepted: 04/04/06 


\section{Introduction}

Hearing loss is one of the commonest birth defects. It is the third leading chronic disability following arthritis and hypertension [1]. Hearing impairment is a pervasive disability affecting nearly 250 million people in the world, and $75 \%$ of sufferers live in developing countries [2]. Hearing loss has become a common problem in industrialized societies due to the combined effects of noise, ageing and heredity. Infection is an added factor contributing to hearing loss in developing countries. In other words, the problem is global.

The impact of hearing loss on the individual and society is significant. Development of hearing loss leads to severe handicap that affects the sufferer's job, home and life with subsequent social and economic burden on the society. In children the problem is compounded since normal hearing is the primary source for acquisition of language, speech and cognitive skills.

There is no database about the magnitude and distribution of the hearing impairment problem in Egypt. A few academic studies confined to specific age groups or certain geographical areas have been conducted. Prevalence of hearing loss in schoolchildren was found to be $5.3 \%$ in Alexandria [3] and $4.5 \%$ in rural areas [4]. A more recent study found hearing loss among $13.7 \%$ of schoolchildren in Ismailia governorate [5], but they used only tympanometry to test for middle ear diseases.

In order to plan for the prevention and management of hearing loss, the World Health Organization (WHO) and the Ministry of Health and Population took the initiative to conduct a household national survey of hearing loss in Egypt. The outcome of the survey will help set the strategies and policies for hearing and ear care in Egypt. The national hearing survey in Egypt had the following objectives: to estimate the preva- lence of hearing impairment and deafness among the Egyptian population; to study the causes of hearing impairment in relation to epidemiological parameters; to assess the availability of ear, nose and throat (ENT) and audiological services; and to suggest steps for the development of protocols for prevention and treatment of hearing loss to reduce deafness at the national level. This paper reports the prevalence of hearing impairment and deafness among the Egyptian population and the causes of hearing impairment in relation to epidemiological parameters.

\section{Methods}

\section{Sample selection}

This survey was a household survey targetting the whole Egyptian population which is around 68.6 million according to the 2002 population census. A sample was chosen based on the multistage stratified clustering technique. The strata were the Egyptian governorates. Statistical representation was based on 6 governorates as previous national projects sponsored by WHO have been carried out in only 4-6 governorates. Random sampling selected the following 6 governorates: Alexandria, Dakahlia, Luxor, Marsa Matrouh, Minia and North Sinai. Clusters started at the level of districts and went down to apartments/place of residence which were considered the end-sampling units. At each level of sampling, simple or systematic random sampling techniques were used for randomization and representativeness of the sample.

According to the estimated prevalence of hearing impairment derived from previous local studies [3-5], the minimum sample size required with $95 \%$ confidence interval and $1 \%$ error was 4000 individuals. As the population size differs from one governorate to another, selection was made 
proportionate to size of the governorates. As the average number of residents in each unit in Egypt is 5.2 then a minimum of 800 households were selected to reach the required sample size (Alexandria 1202, Dakahlia 1432, Luxor 117, Marsa Matrouh 74, Minia 1101 and North Sinai 74). The sample was also adjusted according to the sex and age distributions of the Egyptian population.

\section{Data collection}

The survey was conducted in 2 phases. Phase I was the field study to screen for hearing loss. The test battery included history-taking, ear examination, otoacoustic emission (OAE) tests and tympanometry. It is noteworthy to mention that the WHO recommendation is pure-tone audiometry, which is not suitable for children below 4 years of age [6]. The current recommendation is to use the OAE for screening as this is rapid, objective, needs minimum cooperation of the subject being examined, is easily taught to a nurse or technician and gives uniform data. The technique used in this survey was multifrequency distortion product OAE. Impedance audiometry was also used to test the middle ear and Eustachian tube functions. The WHO ear and hearing disorders survey protocol with its forms and software material were used to conduct the survey [6].

Those individuals who were identified as having hearing loss in Phase I were included in phase II for further evaluation of their hearing problem. Patients were referred to tertiary centres where all or part of the following was carried out depending on the patient's diagnosis: microscopic ear examination, full audiological studies (pure tone or brainstem audiometry depending on the age), computed tomography scan, and laboratory and genetic testing. The standard reference used to assess the degree of hear- ing loss was the American standard adopted by the American Speech-Language-Hearing Association [7] which uses the following degrees of hearing loss and decibel (db) cut-offs (indicating the softest intensity that sound is perceived): mild $(25-40 \mathrm{db})$, moderate (40-55 db), moderately severe $(55-70 \mathrm{db})$, severe $(70-90 \mathrm{db})$ and profound (>90 db).

The field team was composed of audiologists and ENT specialists. The personnel involved in the study had various stages of training following the steps and phases of the survey. This ensured the standardization of the procedures, data acquisition, recording and analysis.

The data collected were processed and analysed using the SPSS, version 11 . Descriptive statistics, chi-squared tests and nonparametric tests when applicable were used to study the associations between hearing impairment and related risks. Significance was set at the $5 \%$ level.

\section{Results}

The hearing loss detected in phase I was $19.81 \%$ of the tested sample. Hearing loss detected in phase II was $16.02 \%$. Therefore there were $3.60 \%$ (144 subjects) false positive results with OAE.

Comparison between the governorates and the whole sample as regards occurrence of hearing loss showed a very significant statistical difference $\left(\chi^{2}=30.14, P<0.001\right)$, indicating differences in the occurrence of hearing loss between governorates. Comparing each governorate with the total sample there was a significant difference between the total sample and Alexandria, Daqahilia and Marsa Matrouh governorates. Also by calculating the $95 \%$ confidence interval for each governorate separately, it is clear that Alexandria, Daqahilia and Minia results 
are nearest to the true estimate of the whole population of those governorates (Table 1).

There was no statistically significant difference in the sex distribution among the different age groups or between different governorates $\left(\chi^{2}=6.07, P=0.53\right)$. Thus sex had no effect on the occurrence of hearing loss across different age groups. However there was a significant statistical difference in the occurrence of hearing loss both in males $\left(\chi^{2}=105.40, P<0.001\right)$ and females $\left(\chi^{2}=164.44, P<0.001\right)$ between the age groups (Table 2). Thus age had an effect on the occurrence of hearing loss. There were 2 peaks of higher frequency of hearing loss: 0-4 years $(22.4 \%)$ and $>65$ years $(49.3 \%)$. Moreover, there was a statistically significant difference in the absolute age between the normal population and those with hearing loss in males (Kruskal-Wallis $\mathrm{H}=11.38, P<0.001$ ) and females (Kruskal-Wallis $\mathrm{H}=50.61, P$ $<0.001$ ) indicating that age was probably higher in the hearing loss group.

Bilateral hearing loss was present in $75.98 \%$ of those with hearing loss and unilateral hearing loss was present in $24.02 \%$ (12.2\% and $3.8 \%$ of the whole sample respectively). The frequency of right ear hearing loss was $86.7 \%$ and left ear hearing loss was $89.2 \%$ out of the 641 subjects diagnosed with hearing loss. Table 3 shows that in each age group the frequency of bilateral hearing loss was statistically significantly higher than unilateral hearing loss $\left(\chi^{2}=\right.$ 52.52, $P<0.001$ ). In unilateral hearing loss there was no statistically significant effect of age on hearing loss being right or left ear hearing loss $\left(\chi^{2}=6.30, P=0.5\right)$.

Hearing loss tends to be a bilateral condition: a fact that increases the burden of the problem. The frequency of bilateral "advanced" hearing loss, which includes severe, profound and total hearing loss, occurred in $8.3 \%$ of those with hearing loss (Table 4).

Conductive hearing loss was found in $64.1 \%$ of the group with hearing loss ( $10.3 \%$ of the whole sample), sensorineural hearing loss in $33.5 \%$ (5.4\% of the whole sample) and the mixed type in $2.3 \%(0.4 \%$ in whole sample) (Table 5) There was no statistically significant difference between males and females in the frequency of the different types of hearing loss.

There was a statistically significant difference in the degree of hearing loss in right ears by age group $\left(\chi^{2}=137.46, P<0.001\right)$

\begin{tabular}{|c|c|c|c|c|c|c|}
\hline \multirow[t]{2}{*}{ Governorate } & \multicolumn{2}{|c|}{ Total sample } & \multirow{2}{*}{$\begin{array}{c}\text { Normal } \\
\text { hearing } \\
\text { No. }\end{array}$} & \multicolumn{2}{|c|}{ Hearing loss } & \multirow[t]{2}{*}{$95 \% \mathrm{Cl}$} \\
\hline & No. & $\%$ & & No. & $\%$ & \\
\hline Dakahlia & 1432 & 35.80 & 1196 & 196 & 13.69 & $2.35-3.56$ \\
\hline Alexandria & 1202 & 30.05 & 914 & 242 & 20.13 & $2.46-10.03$ \\
\hline Minia & 1101 & 27.53 & 914 & 152 & 13.81 & $1.1-2.52$ \\
\hline Luxor & 117 & 2.92 & 84 & 22 & 18.80 & $2.9-6.66$ \\
\hline Marsa Matrouh & 74 & 1.85 & 47 & 19 & 25.68 & $8.42-10.2$ \\
\hline North Sinai & 74 & 1.85 & 60 & 10 & 13.51 & $2.53-8.42$ \\
\hline Total & 4000 & 100.0 & 3215 & 641 & 16.02 & \\
\hline
\end{tabular}

aThis excludes 144 false-positives identified in Phase I.

$\mathrm{Cl}=$ confidence interval. 


\begin{tabular}{|c|c|c|c|c|c|c|}
\hline \multirow{3}{*}{$\begin{array}{l}\text { Age group } \\
\text { (years) }\end{array}$} & \multirow{3}{*}{$\begin{array}{l}\text { Total } \\
\text { sample } \\
\text { No. }\end{array}$} & \multicolumn{2}{|c|}{ Males } & \multicolumn{3}{|c|}{ Females } \\
\hline & & \multicolumn{2}{|c|}{ Hearing loss } & \multirow{2}{*}{$\begin{array}{c}\text { Total } \\
\text { sample } \\
\text { No. }\end{array}$} & \multicolumn{2}{|c|}{ Hearing loss } \\
\hline & & No. & $\%$ & & No. & $\%$ \\
\hline 00-04 & 264 & 61 & 23.11 & 232 & 50 & 21.55 \\
\hline 05-14 & 581 & 71 & 12.22 & 520 & 39 & 7.507 \\
\hline $15-24$ & 380 & 37 & 9.74 & 398 & 43 & 10.80 \\
\hline $25-34$ & 263 & 29 & 11.03 & 274 & 31 & 11.31 \\
\hline $35-44$ & 220 & 34 & 15.45 & 216 & 33 & 15.28 \\
\hline $45-54$ & 150 & 34 & 22.67 & 156 & 37 & 23.72 \\
\hline $55-64$ & 101 & 33 & 32.67 & 95 & 35 & 36.84 \\
\hline$\geq 65$ & 71 & 34 & 47.89 & 79 & 40 & 50.63 \\
\hline Total & 2030 & 333 & 16.40 & 1970 & 308 & 15.63 \\
\hline
\end{tabular}

and by absolute age when tested by nonparametric methods (Kruskal-Wallis $\mathrm{H}=$ $92.97, P<0.001)$ indicating that age had an effect on the degree of hearing loss (Table 6). Similar results were obtained for the left ear (data available on request).

We identified 19 causes of hearing loss in the current survey; 9 were related to conductive hearing loss and 10 were sensorineural hearing loss. Table 7 shows the common causes of hearing loss found in the study. The 3 commonest causes were otitis media with effusion $(30.7 \%)$, presbycusis $(22.7 \%)$ and chronic suppurative otitis media $(13.2 \%)$.

Individuals found to have hearing loss required different lines of management (Table 8). Most of the group needed medical treatment $(250 / 641,39.0 \%)$ and 159 $(24.8 \%)$ needed hearing aids: 114 needed bilateral treatment and 45 unilateral. Of those who needed hearing aids before the

Table 3 Unilateral and bilateral hearing loss by age group

\begin{tabular}{|c|c|c|c|c|c|c|c|c|c|}
\hline \multirow{2}{*}{$\begin{array}{l}\text { Age group } \\
\text { (years) }\end{array}$} & \multirow{2}{*}{$\begin{array}{l}\text { Hearing } \\
\text { loss } \\
\text { No. }\end{array}$} & \multicolumn{2}{|c|}{ Bilateral } & \multicolumn{2}{|c|}{ Unilateral } & \multicolumn{2}{|c|}{ Right ear } & \multicolumn{2}{|c|}{ Left ear } \\
\hline & & No. & $\%$ & No. & $\%$ & No. & $\%$ & No. & $\%$ \\
\hline 00-04 & 111 & 89 & 80.18 & 22 & 19.82 & 11 & 50.0 & 11 & 50.0 \\
\hline 05-14 & 110 & 85 & 77.27 & 25 & 22.73 & 13 & 52.0 & 12 & 48.0 \\
\hline $15-24$ & 80 & 47 & 58.75 & 33 & 41.25 & 12 & 36.36 & 21 & 63.64 \\
\hline 25-34 & 60 & 35 & 58.33 & 25 & 41.67 & 14 & 56.0 & 11 & 44.0 \\
\hline $35-44$ & 67 & 42 & 62.69 & 25 & 37.31 & 12 & 48.0 & 13 & 52.0 \\
\hline $45-54$ & 71 & 59 & 83.1 & 12 & 16.9 & 3 & 25.0 & 9 & 75.0 \\
\hline $55-64$ & 68 & 60 & 88.24 & 8 & 11.76 & 2 & 25.0 & 6 & 75.0 \\
\hline$\geq 65$ & 74 & 70 & 94.59 & 4 & 5.41 & 2 & 50.0 & 2 & 50.0 \\
\hline Total & 641 & 487 & 75.98 & 154 & 24.02 & 69 & 44.81 & 85 & 55.19 \\
\hline
\end{tabular}


Table 4 Categories of advanced bilateral hearing loss $(\mathrm{HL})$ in the sample

\begin{tabular}{lcc}
\hline Category & No. $(\boldsymbol{n}=\mathbf{6 4 1})$ & \% \\
\hline Bilateral severe HL & 39 & 6.08 \\
Bilateral profound HL & 7 & 1.09 \\
Bilateral dead ears & 2 & 0.31 \\
Any 2 & 5 & 0.78 \\
Total & 53 & 8.27 \\
\hline
\end{tabular}

survey, only $8.8 \%$ (14 out of 159$)$ used them. Surgical treatment for hearing loss was needed by 143 of the 641 subjects $(22.3 \%)$ : the commonest indications were middle ear infections and otosclerosis. There were only $7(1.1 \%)$ individuals who had had speech training, however $11 \%$ actually needed such training. There were 11 patients who could benefit from cochlear implants. Of these, 8 were under 20 years ( 7 had congenital or hereditary hearing loss and were prelingual; 1 had hearing loss caused by auto-immune disease and was post-lingual) and 3 patients were $>50$ years ( 2 who were 50 and 73 years had presbycusis and 1 who was 67 years had noise-induced hearing loss).
Table 9 shows the distribution of the hearing loss according to hearing aid needs in the left ear and surgical needs, and age group.

\section{Discussion}

In Egypt there have been no national surveys on the prevalence of hearing loss and deafness. There have been hospital-based and academic studies which give an idea about the magnitude of the problem $[3-5,8,9]$. The current survey shows that the prevalence of hearing loss in Egypt (16.02\%) is higher than many other countries, both developed countries such as the United States $(9.6 \%)$ [10] and developing countries such as Indonesia (4.6\%) and Sri Lanka $(8.8 \%)$ [11]. The rate is also higher than that of Oman (5.53\%) [12] and Saudi Arabia (13\%) [13], which as Arab countries have ethnic, cultural and traditional similarities to Egypt. It should be noted that the Saudi study included children only.

There was a significant difference in the occurrence of hearing loss between the different governorates selected. This

\begin{tabular}{|c|c|c|c|c|c|c|c|c|c|}
\hline \multirow[t]{2}{*}{$\begin{array}{l}\text { Age group } \\
\text { (years) }\end{array}$} & \multirow{2}{*}{$\begin{array}{c}\text { Total } \\
\text { sample } \\
\text { No. }\end{array}$} & \multicolumn{2}{|c|}{ Hearing loss } & \multicolumn{2}{|c|}{$\begin{array}{c}\text { Conductive } \\
\text { hearing loss }\end{array}$} & \multicolumn{2}{|c|}{$\begin{array}{l}\text { Sensorineural } \\
\text { hearing loss }\end{array}$} & \multicolumn{2}{|c|}{ Mixed } \\
\hline & & No. & $\%$ & No. & $\%$ & No. & $\%$ & No. & $\%$ \\
\hline 00-04 & 496 & 111 & 22.38 & 100 & 20.16 & 11 & 2.22 & 0 & 0.0 \\
\hline 05-14 & 1101 & 110 & 9.99 & 90 & 8.17 & 20 & 1.82 & 0 & 0.0 \\
\hline $15-24$ & 778 & 80 & 10.28 & 59 & 7.58 & 20 & 2.57 & 1 & 0.13 \\
\hline $25-34$ & 537 & 60 & 11.17 & 52 & 9.68 & 8 & 1.49 & 0 & 0.0 \\
\hline $35-44$ & 436 & 67 & 15.37 & 50 & 11.47 & 15 & 3.44 & 2 & 0.46 \\
\hline $45-54$ & 306 & 71 & 23.2 & 36 & 11.76 & 34 & 11.11 & 1 & 0.33 \\
\hline $55-64$ & 196 & 68 & 34.69 & 19 & 9.69 & 46 & 23.47 & 3 & 1.53 \\
\hline$\geq 65$ & 150 & 74 & 49.33 & 5 & 3.33 & 61 & 40.66 & 8 & 5.33 \\
\hline Total & 4000 & 641 & 16.02 & 411 & 10.25 & 215 & 5.36 & 15 & 0.37 \\
\hline
\end{tabular}

Percentages are related to total sample. 


\begin{tabular}{lccccccccccc}
\hline \multicolumn{10}{l}{ Table 6 Degree of hearing loss in right ears by age group } \\
\hline $\begin{array}{l}\text { Age group } \\
\text { (years) }\end{array}$ & $\begin{array}{c}\text { Hearing } \\
\text { loss }\end{array}$ & \multicolumn{1}{c}{ No. } & Nild & \multicolumn{1}{c}{ Moderate } & \multicolumn{1}{c}{ Severe } & \multicolumn{1}{c}{ Profound } & \multicolumn{2}{c}{ Dead } \\
\hline $00-04$ & 97 & 77 & 79.4 & 15 & 15.5 & 1 & 1.0 & 4 & 4.1 & 0 & 0 \\
$05-14$ & 102 & 81 & 79.4 & 11 & 10.8 & 7 & 6.9 & 1 & 0.9 & 2 & 2.0 \\
$15-24$ & 59 & 41 & 69.5 & 13 & 22.0 & 4 & 6.8 & 1 & 1.7 & 0 & 0 \\
$25-34$ & 49 & 36 & 73.5 & 12 & 24.5 & 1 & 2.0 & 0 & 0 & 0 & 0 \\
$35-44$ & 53 & 36 & 67.9 & 14 & 26.4 & 3 & 5.7 & 0 & 0 & 0 & 0 \\
$45-54$ & 62 & 36 & 58.1 & 21 & 33.9 & 4 & 6.5 & 0 & 0 & 1 & 1.6 \\
$55-64$ & 62 & 26 & 41.9 & 29 & 46.8 & 6 & 9.7 & 0 & 0 & 1 & 1.6 \\
$\geq 65$ & 72 & 12 & 16.7 & 38 & 52.8 & 19 & 26.4 & 3 & 4.2 & 0 & 0 \\
Total & $556^{a}$ & 345 & 62.1 & 153 & 27.5 & 45 & 8.1 & 9 & 1.6 & 4 & 0.7 \\
\hline
\end{tabular}

${ }^{a}$ This comprises individuals with any right ear hearing loss irrespective of whether it was unilateral or bilateral.

difference could be attributed to the differences in hearing loss in each age group, especially presbycusis in the older groups. The highest rate of hearing loss was found in Marsa Matrouh $25.68 \%$ followed by Alexandria $20.13 \%$ and the lowest in North Sinai $13.51 \%$. Noise could not explain the difference since North Sinai and Marsa Matrouh are both coastal areas and not noisy environments. It should be noted that both areas with the highest frequency of hearing loss were screened by the same team and it is possible that this could have made a difference.

Sex had no effect on the occurrence or any other parameters of hearing loss. However, age had a significant role in the occurrence of hearing loss. It is well known that physiologically hearing loss increases with ageing and our results bear this out.

\begin{tabular}{|c|c|c|c|c|}
\hline \multirow[t]{2}{*}{ Cause } & \multicolumn{2}{|c|}{ Right $(n=556)$} & \multicolumn{2}{|c|}{ Left $(n=572)$} \\
\hline & & $\%$ & No. & $\%$ \\
\hline Otitis media with effusion & 171 & 30.76 & 176 & 30.77 \\
\hline Presbycusis & 133 & 23.92 & 130 & 22.73 \\
\hline $\begin{array}{l}\text { Chronic suppurative otitis } \\
\text { media }\end{array}$ & 66 & 11.87 & 76 & 13.29 \\
\hline Eustachian dysfunction & 51 & 9.17 & 51 & 8.92 \\
\hline Congenital/genetic & 35 & 6.29 & 34 & 5.94 \\
\hline Otosclerosis & 34 & 6.12 & 34 & 5.94 \\
\hline Adhesive otitis media & 22 & 3.96 & 21 & 3.67 \\
\hline
\end{tabular}




\begin{tabular}{lrc}
\hline \multicolumn{3}{l}{$\begin{array}{l}\text { Table } 8 \text { Management of hearing loss in those } \\
\text { diagnosed with the condition }\end{array}$} \\
\hline Management & \multicolumn{2}{c}{ Total requiring } \\
treatment $(\boldsymbol{n}=\mathbf{6 4 1})$ \\
No. & $\%$ \\
\hline Medical treatment & 250 & 39.0 \\
Hearing aids & 159 & 24.8 \\
Surgery & 143 & 22.3 \\
Further investigations & 42 & 6.5 \\
Speech training & 7 & 1.1 \\
Cochlear implant & 1 & 0.2 \\
Ear wash & 350 & 54.6 \\
\hline
\end{tabular}

The fact that the age group $0-4$ years had a high frequency of hearing loss $(22.4 \%)$ should draw attention to the importance of screening this age group: this should include neonatal screening and preschool screening. The identification of hearing problems earlier carries the best prognosis for treatment and rehabilitation through speech and language training and hearing aids. A neonatal screening programme

\begin{tabular}{lrrrr}
\hline \multicolumn{3}{l}{$\begin{array}{l}\text { Table } 9 \text { Distribution of the sample according } \\
\text { to hearing aids and surgery needed by age } \\
\text { group }\end{array}$} \\
$\begin{array}{lrrrr}\text { Age group } \\
\text { (years) }\end{array}$ & $\begin{array}{l}\text { Hearing aid } \\
\text { needed } \\
\text { No. }\end{array}$ & \multicolumn{3}{c}{$\begin{array}{l}\text { Surgery } \\
\text { needed }\end{array}$} \\
& 14 & 8.8 & 1 & 0.7 \\
\hline $00-04$ & 10 & 6.3 & 14 & 9.8 \\
$05-14$ & 5 & 3.1 & 28 & 19.6 \\
$15-24$ & 5 & 3.1 & 30 & 21.0 \\
$25-34$ & 2 & 1.3 & 39 & 27.3 \\
$35-44$ & 21 & 13.2 & 23 & 16.1 \\
$45-54$ & 40 & 25.2 & 5 & 3.5 \\
$55-64$ & 62 & 39.0 & 3 & 2.1 \\
$\geq 65$ & 159 & 100.0 & 143 & 100.0 \\
\hline Total & & & & \\
\hline
\end{tabular}

at Ain Shams University [14] found 5\% of neonates had hearing loss screened by OAE, which compares with $2.5 \%$ in the current study. The higher incidence in the Ain Shams study may be due to differences in the sample and possible false positive results with OAE.

The prevalence of hearing loss in schoolchildren (6-12 years) was almost $10 \%$ which is higher than rates reported in previous studies in the country of 5.3\% [3] and $4.5 \%$ [4]. Attention should be directed to what has caused such an increase and how to tackle this issue.

International statistics for children with hearing impairment are reported to be 2-6/1000 live birth [15]. Bess et al. [16] reported $11.3 \%$ prevalence of minimal sensorineural hearing loss in school-age children and Niskar et al. [17] found that $14.9 \%$ of children had either low frequency or high frequency hearing loss in a hospital-based study. In the Saudi study the prevalence of hearing loss in age group 5-15 years was $13 \%$ and the commonest cause was otitis media with effusion [13]. As for adults, in the United States [18] hearing loss prevalence was: $4.6 \%$ in those aged $18-44$ years (our data $12.9 \%$ ), 14\% in those 45-64 years (our data $27.7 \%$ ) and $54 \%$ in those over 65 years (our data $49.3 \%$ ). Our figures are higher in the younger age groups but the same for those over 65 years. It seems that age has the same effect in both societies, but there are different causes in the younger groups, for example different infection rates, particularly otitis media in children.

Neither the side of the disease nor the sex had an effect on the degree of hearing loss. Age however did have an effect; younger ages had milder degree of hearing loss, older subjects had more severe hearing loss. Hearing loss is usually difficult to detect due to its "invisible" nature. Mild 
hearing losses may not be noticed and even moderate losses may not impose a problem for people with excellent perceptual abilities and good coping skills. However, children are different and the problem is more complex since many children are considered to be suffering from psychological problems and in fact their psychological problems are due to hearing loss. Therefore, the early diagnosis requires screening programmes in order to identify those with hearing impairment.

In Egypt previous studies have pointed to hereditary and infection as the main etiologies of hearing loss [19]. It is reported that in the Western literature about $24 \%-39 \%$ of the causes of hearing loss are due to genetic factors [19]. In the current survey the commonest cause was otitis media with effusion which accounted for $30.7 \%$ of people with hearing impairment: the peak age group was $0-4$ years followed by $5-14$ years. The condition usually starts as acute otitis media which is very frequent before the age of 3 years and almost $75 \%$ of children before the age of 10 years would have experienced 1 or more attacks of acute otitis media $[20,21]$. The commonest sequela of acute otitis media is otitis media with effusion with conductive hearing loss.

Chronic suppurative otitis media without cholesteatoma was the cause of hearing loss in $17.6 \%$ of cases. Eustachian tube dysfunction had 2 peaks at 5-25 years and $35-45$ years. The highest was at 5-14 years which explains the high incidence of otitis media with effusion in this age group and higher incidence of chronic suppurative otitis media in the later age group.

Most of the causes of hearing loss, whether congenital, traumatic or inflammatory, are preventive. Patients suffering form degenerative and neoplastic causes of hearing loss can be rehabilitated. Accordingly, diagnosis and early detection of the causes of hearing loss is vital in order to prevent, cure, stabilize or rehabilitate such cause of hearing loss.

A large proportion of our sample with hearing loss (39\%) needed medical treatment. This indicates that hearing loss is mainly a medical problem. Therefore, the prevalence of hearing loss can be decreased by improvement of the diagnostic and treatment abilities of health providers especially at the primary care level, where the costs needed to tackle the problem should not be high.

About $25 \%$ of our sample needed hearing aids. Of those who already knew they needed hearing aids, only $8.8 \%$ used them. Patients may have refused using hearing aids for cosmetic, traditional or cost reasons or aids were not available. The infrequent use of hearing aids is a very serious issue, especially among the younger age groups who need language development: in the age group 0-4 years in our sample $8.6 \%$ needed hearing aids. In the United States only $20 \%$ of those who may benefit from hearing aids wear them [22]. Approximately 12 million Americans use hearing aids but of these only 8 million use them regularly. It seems that people around the globe have the same attitude towards the use of hearing aids.

Language and speech training was needed by $11 \%$ of our sample but only $1.1 \%$ were receiving it. There is a great need therefore for the provision of services for speech and language training and for more qualified personnel, especially in remote areas.

Surgery was needed by $22.3 \%$ of our sample. The commonest age groups needing surgery were from 15 to 45 years. These are among the productive working years of people. The commonest indication for surgery was middle ear infection but most such ear infections can be prevented or the predisposing factors can be treated early. If this is done, then such surgery can be avoided thus reducing costs and decreasing absent days 
from work and school. Therefore, the health authorities should improve the primary care services regarding diagnostic and medical treatment of ear infections.

Cochlear implants are needed for patients with bilateral profound to total hearing loss who cannot be fitted with hearing aids $[23,24]$. Because treatment with cochlear implants is expensive (Egyptian pounds 150 000-200 000; US\$ $1=5.7$ EGP) then it is better to implant younger patients. A study at Ain Shams University found that 67 per 10000 population suffered from severe disabling hearing loss [19]. It was also found that $30 \%$ of this population did not benefit from hearing aids and needed cochlear implants $(0.2 \%)$ which is the same found in our sample.

\section{Recommendations}

The Ministry of Health and Population should focus on hearing screening in neonates and preschool children in the future health planning since there was a high incidence of hearing loss in these young age groups.
Since medical treatment is the mainstay of hearing loss management, improvement of the diagnostic and treatment skills of health service providers, especially at the primary care level, could considerably reduce the incidence of the hearing loss. The health authorities should integrate hearing and ear care in primary care centre programmes. Such care will decrease the direct and indirect cost of the hearing impairment problem.

The media and nongovernmental organizations should play a role in patient education and awareness of the hearing loss problem and focus on the use of hearing aids. The government needs to increase the subsidy of hearing aids. Since the cost of cochlear implants is high and most of the causes can be prevented, attention should be directed to preventive programmes.

\section{Acknowledgement}

This work was supported by a grant from the World Health Organization Regional Office for the Eastern Mediterranean.

\section{References}

1. Collins JG. Prevalence of selected chronic conditions: United States 1990-1992. National Centre for Health Statistics. Vital and health statistics, 1997, 10(194):189.

2. Deafness and hearing impairment. Geneva, World health Organization, 2006 (WHO Fact sheet No. 300).

3. Riad S. A study of the hearing status of school children in Alexandria Governorate [MD thesis]. Alexandria, University of Alexandria, 1975.

4. Kolta O. The hearing profile of subjects in a rural community in Qualyb area [MD thesis]. Cairo, Ain Shams University, 1982.
5. Hussein N. Prevalence of hearing loss among school children in Ismalia governorate [Master thesis]. Cairo, Ain Shams University, 1996.

6. Occupational exposure to noise: evaluation, prevention and control: edited by $\mathrm{Be}$ renice Goelzer, Colin H. Hansen, Gustav A. Sehrndt. Dortmund, Germany, World Health Organization, 2001 (published by the Federal Institute for Occupational Safety and Health (Germany) on behalf of the World Health Organization).

7. American Speech-Language-Hearing Association. Type, degree, and configuration of hearing loss. (http://www.asha. 
org/public/hearing/disorders/types.html, accessed 9 September 2006).

8. Khalafalla A. Immittance screening in school children [Master thesis]. Cairo, Ain Shams University, 1992.

9. Sami H. Hearing loss among Egyptian children. Etiology and psychological aspects [Master thesis]. Cairo, Ain Shams University, 1990.

10. Adams PF, Hendershot GE, Marano MA. Current estimates from the National Health Interview Survey, 1996. Hyattsville, National Centre for Health Statistics, 1999.

11. Prevention and control of deafness and hearing impairment. Report of an intercountry consultation, Colombo, Sri Lanka 2002. New Delhi, WHO Regional Office for South-East Asia, 2003.

12. National survey for causes of deafness and common ear diseases in Oman: WHO program for prevention of blindness and deafness. Muscat, Ministry of Health, 1997.

13. Zakzouk SM, Al-Anazy F. Sensorineural hearing impaired children with unknown causes: a comprehensive etiological study. International journal of pediatric otorhinolaryngology, 2002, 64(1)17-21.

14. Tawfik S, Hazza N. Hearing screening in neonates: Ain Shams Experience. Paper presented at the annual meeting of the Egyptian Otorhinolaryngological Society, Cairo, Egypt, September, 2004

15. Parving A. The need for universal neonatal hearing screening: some aspects of epidemiological and identification. Acta pediatrica (suppl.), 1999, 88(432):69-72.

16. Bess FH, Dodd-Murphy J, Parker RA. Children with minimal sensorineural prev- alence, educational performance and functional status. Ear and hearing, 1998, 19(5):339-54.

17. Niskar AS et al. Prevalence of hearing loss among children 6-19 years of age: the 3rd national health and nutrition examination survey. Journal of the American Medical Association, 1998, 279(14):1071-5.

18. The prevalence and incidence of hearing loss in adults. Rockville, American Speech-Language-Hearing Association, 1997-2005.

19. Kamal, N. Profound hearing loss in Egyptian children. Egyptian journal of surgery, 1990, 9(2):49-52.

20. Alsarraf R, Jung CJ, Perkins J. Otitis media health status evaluation: A pilot study for the investigation of cost-effective outcomes of recurrent acute otitis media treatment. Annals of otology, rhinology and laryngology, 1998, 107(2):120-8.

21. Schappert SM. Office visits for otitis media: United States, 1975-90. Advance data, 1992, 13(137):17.

22. Popelka MM, Cruickshanks KJ, Wiley TL. Low prevalence of hearing aid use among older adults with hearing loss: The Epidemiology of Hearing Loss Study. Journal of the American Geriatrics Society, 1998, 46(9):1075-8.

23. Arts H, Garber A, Zwolen A. Cochlear implants in young children. Otolaryngologic clinics of North America, 2002, 35:92543.

24. Tharwat A et al. Cochlear implants selection criteria in adults. Paper presented at the Cochlear Implant Symposium, Cairo, 1998. 